\title{
O Des(P)EJo Que Me Habita - A PSicanÁlise E @S Voltas
}

\author{
Claudia Aparecida de Oliveira Leite ${ }^{1}$
}

\section{RESUMO:}

O livro Quarto de despejo, de Carolina Maria de Jesus, impactou a sociedade por revelar a realidade da favela. Sendo assim, aquilo que deveria permanecer escondido vem à luz revelando um "fruto estranho". Recuperamos o primeiro anúncio que Freud nos traz em seu trabalho Das Unheimliche (1919), quando ele ressalta que estamos na fronteira da estética ao nos ocuparmos do tema do estranho. Porém, o modo como a Psicanálise se aproxima desse tema revela seu aspecto fugidio e radicalmente intraduzível. O presente trabalho circula entre o que Freud nos ensina sobre o estranho e o que Carolina denuncia com sua letra: a estreita relação entre a escrita e o corpo. Nesse sentido, articulamos o estranho em três tempos: Tempo de ler, Tempo de escrever e Tempo de estranhar.

PalAVRAs-Chave: Carolina Maria de Jesus. Corpo. Escrita. Estranho. Psicanálise.

\footnotetext{
1 Possui graduação em Psicologia pela Universidade Federal de Minas Gerais, especialização em Psicopedagogia Clínica e Institucional (FUNEDI-UEMG), mestrado em Linguística (2004) e doutorado em Linguística pela Universidade Estadual de Campinas. Pós-doutorado em Clínica Psicanalítica do Sujeito e do laço social (Laboratoire Clinique Psychopatologique et Interculturelle / Université Toulouse II - Mirail). Pesquisadora associada do Centro de Pesquisa Outrarte (IEL/Unicamp), membro do Projeto \$EMA\$OMa ( IEL/UNICAMP). Pesquisadora do Grupo de Pesquisa "Psicanálise: clínica, política e cultura" (UFBA). Docente do Curso de Psicologia da UEMG - Divinópolis. Membro fundadora do Parlêtre: Psicanálise, Pesquisa e Transmissão (Divinópolis /MG). Endereço: Rua Resplendor, 57 Bairro Bom Pastor Divinópolis Minas Gerais Brasil. Telefone: (37) 984019692. ORCID: https://orcid.org/00000002-1634-4866 .
} 
14 de março de 1914. Sacramento, Minas Gerais. Nasce Carolina Maria de Jesus. Negra, pobre, literata, descendente dos escravos que haviam sido liberados 26 anos antes, em 1888. Curiosamente, no dia 14 de março, nós comemoramos o aniversário de outro poeta: Castro Alves, Poeta dos Escravos, que nasceu em 1847 e, muito provavelmente, por causa desse último, nós celebramos, no dia 14 de março, o Dia da Poesia.

Nesse trabalho, entretanto, o lugar da poesia será ocupado pelas letras de Carolina, particularmente, por aquelas estampadas em seu diário de uma favelada. Essa aventura poética será o fio condutor que nos guiará pelo texto que Freud construiu em 1919, nomeado Das Unheimliche. Intraduzível, Das Unheimliche é transliterado por: $\mathrm{O}$ estranho, $\mathrm{O}$ inquietante, $\mathrm{O}$ familiarmente estranho, Ex-tranho, $\mathrm{O}$ infamiliar. O "Quarto de despejo", de Carolina e Das Unheimliche, de Freud, serão articulados em dois pontos de ancoragem: o DES( $p)$ EJO e as voltas da Psicanálise. Para tal, dividiremos esse artigo em três tempos: 1ㅇ) Tempo de ler; 2ํ) Tempo de escrever e 3 o) Tempo de estranhar. Esses tempos merecem ser tomados em uma perspectiva lógica, pois se embaraçam continuamente.

Sobre o "Tempo de ler", queremos recuperar as duas leituras supracitadas: "Quarto de despejo: diário de uma favelada" e "O Estranho" (Das Unheimliche). As duas leituras aconteceram no ano de 2018. Ano em que comemoramos no Brasil os 130 anos da assinatura da Lei Áurea. Ano deveras turbulento. Ano de severas rupturas sociais. A abolição da escravidão brasileira traz, para muitos, um sentimento infamiliar, que ora se estabelece como um desejo de comemorar e ora se revela pela indignação diante da espera de uma efetiva reparação social. Nesse cenário, encontramos o Quarto de despejo.

"Quarto de despejo: diário de uma favelada", foi o primeiro livro publicado por Carolina Maria de Jesus, em 1960. Se naquela época as tiragens de livros circulavam em torno dos singelos 3.000 exemplares, Carolina vendeu 30.000 exemplares do seu livro na primeira edição e alcançou a venda de 100.000 exemplares nas edições posteriores. Um sucesso estrondoso que foi traduzido para 13 idiomas e, obviamente, devorado vorazmente pela indústria literária (DANTAS, 2001).

O que impactou toda sociedade naquela década foi a realidade da favela pobre, negra e desamparada pelo poder público. Carolina vivia na favela do Canindé, em São Paulo, cuidando de seus três filhos. Foi vivendo nesse espaço, à margem, que 
Carolina produziu um "fruto estranho", conforme recolhemos dos dizeres de seu biógrafo Tom Farias, que lançou em 2017, pela editora Malê², o livro "Carolina: uma biografia". E, foi por parir essa escrita, "fruto estranho", que Carolina está aqui, nesse trabalho, nos ajudando a pensar Das Unheimliche. Em meio à miséria, a lucidez das letras nos traz perigosamente pedaços de uma realidade que não deve aparecer. Pois, como podemos descobrir em seu livro, existem algumas realidades que ganham ares de uma reivindicação perigosa demais:

... Fui na sapataria retirar os papeis. Um sapateiro perguntou-me se o meu livro é comunista. Respondi que é realista. Ele disse que não é aconselhavel escrever a realidade. (JESUS, 2001 [1960], p.96) ${ }^{3}$

Seria de um "fruto estranho" que o sapateiro falava? Fruto estranho que revela a vida-fome (amarela) e que é descrita e escancarada tornando-se, portanto, denúncia viva, traduzida, consumida que afeta a entranha do meio social e político? Pois, o que mais encontramos na escrita de Carolina é a indignação diante de "um passado que insiste em nos rodear". De uma escravidão sem fim. De um desrespeito sem limites que vinha do outro. Ela era profundamente crítica a toda uma classe política bem nutrida que fazia uso da miséria para se manter no poder e na riqueza. Por isso, reivindicava uma representatividade que, tal como ela, tivesse vivenciado a miséria na carne. Almejava em seus escritos: "O Brasil precisa ser dirigido por uma pessoa que já passou fome. A fome também é professora. Quem passa fome, aprende a pensar no próximo e nas crianças" (JESUS, 2001 [1960], p.26). Obviamente, essas palavras desconsertam um certo poder político que se sustenta na desigualdade social.

Nesse tempo de leitura, recortamos algumas questões: O que cada um decide ler? Por que ler Carolina Maria de Jesus? Qual é a estranha posição do leitor diante da narrativa da miséria cotidiana? Pois, no "Quarto de despejo", o leitor também se afunda na lama podre, no beco sem saída, no berro da fome; o leitor também se apazigua com os pedaços de ossos que o frigorífico despejava na terra e que seriam

\footnotetext{
2 Gostaríamos de destacar que Malês (do hauçá málami, "professor", "senhor", no iorubá imale, "muçulmano") era o termo usado no Brasil, no século XIX, para designar os negros muçulmanos que sabiam ler e escrever em língua árabe. Esses eram muitas vezes mais instruídos que seus senhores, e, apesar da condição de escravos, não eram submissos, mas muito altivos.

${ }^{3}$ Manteremos, nas citações de Carolina, a forma escrita original, tal como se encontra no texto da autora.
} 
o principal ingrediente da sopa da noite. Que leitor se funda no despejo de Carolina? Que tempo de ler é esse que se impõe e nos despeja?

Carolina, a própria, nos responde:

... As oito e meia da noite eu já estava na favela respirando o odor dos excrementos que mescla com o barro podre. Quando estou na cidade tenho a impressão que estou na sala de visita, com seus lustres de cristais, seus tapetes de viludo, almofadas de sitim. E quando estou na favela tenho a impressão que sou um objeto fora de uso, digno de estar num quarto de despejo. (JESUS, 2001 [1960], p.33)

O que podemos ler no testemunho de Carolina revela aquilo que deveria ficar escondido, mas veio à tona. Das Unheimliche...? Das Unheimliche é o próprio despejo. E nesse sentido, o diário de Carolina é estranho porque trança corpo (eu) e desejo (sujeito). É assim que cada um contorna a leitura, pois, é assim ela nos conta:

Abri a janela e vi as mulheres que passam rápidas com seus agasalhos descorados e gastos pelo tempo. Daqui a uns tempos estes palitol que elas ganharam de outras e que de há muito devia estar num museu, vão ser substituidos por outros. É os politicos que há de nos dar. Devo incluir-me, porque eu tambem sou favelada. Sou rebotalho. Estou no quarto de despejo, e o que está no quarto de despejo ou queima-se ou joga-se no lixo. (JESUS, 2001 [1960], p.33)

Carolina Maria de Jesus tem um corpo. Ela tem um corpo que circula pela cidade entre outros corpos. Ela olha para o outro e é olhada por aquilo que olha...

8 de novembro ...Fiz arroz e puis agua esquentar para eu tomar banho. Pensei nas palavras da mulher do Policarpo que disse que quando passa perto de mim eu estou fedendo bacalhau. Disse-lhe que eu trabalho muito, que havia carregado mais de 100 quilos de papel e estava fazendo calor. E o corpo humano não presta. Quem trabalha como eu tem que feder!" (JESUS, 2001 [1960], p.119)

Nesse ponto, em que nos deparamos com o fedor do corpo humano que não presta e com a realidade "feia", queremos trançar outra leitura desse primeiro tempo: Das Unheimliche de Sigmund Freud (1919).

Começaremos, então, recuperando do argumento inaugural de Freud nesse texto, sua primeira frase: "Só raramente um psicanalista se sente impelido a pesquisar o tema da estética, mesmo quando por estética se entende não simplesmente a teoria da beleza, mas a teoria das qualidades do sentir" (FREUD, 1996 [1919], p.275). Ele 
prossegue demarcando que o psicanalista deve se interessar, ocasionalmente, por algum ramo particular da estética e conclui dizendo que "o tema do "estranho" é um ramo desse tipo" (idem).

Freud, dessa maneira, inclui o "Estranho" no campo da Estética, da Filosofia, nos advertindo que esse campo prefere se preocupar em seus tratados com o que é belo. Se fizermos uma rápida incursão sobre o tema, percebemos que na via filosófica, conforme nos lembra Talon-Hugon (2009) a Estética abrange diversas definições:

\begin{abstract}
O Dictionnaire Historique et Critique de la Philosophie de A. Lalande (1980) define -a como "a ciência que tem por objecto o juízo da apreciação que se aplica à distinção do belo e do feio", mas o Vocabulaire de l'Esthétique (1990) descreve -a como "a filosofia e (a) ciência da arte"; mais consensuais, Historisches Wörterbuch der Philosophie (1971), Enciclopaedia Filosofica (1967) e Academic American Encyclopaedia (1993) definem-na como o ramo da filosofia que trata das artes e da beleza. (TALON-HUGON, 2009, p. 7)
\end{abstract}

Talon-Hugon (2009) demonstra os desacordos sobre a definição do campo da Estética, uma vez que encontramos entre os filósofos posições diversas. Ele nos lembra, por exemplo que Baumgarten definiu-a como ciência do mundo sensível do conhecimento de um objecto,, enquanto Hegel faz dela a Filosofia da Arte. Segundo o autor, a essa variação ainda se junta o sentido veiculado pela origem do termo, pois Estética vem da palavra grega aisthêsis que designa simultaneamente a faculdade e o ato de sentir, ou seja, a sensação e a percepção.

Cabe ressaltar, portanto que o "ato de sentir" inclui o vasto campo dos afetos. Nesse aspecto, Talon- Hugon (2009) destaca:

Desta cacofonia de definições, sobressaem dois pontos. A estética é uma reflexão sobre um campo de objectos dominado pelos termos "belo", "sensível" e "arte". Cada um destes termos encerra e implica outros e estas séries cruzam -se em diversos pontos: "belo" abre -se para o conjunto das propriedades estéticas; "sensível" remete para sentir, ressentir, imaginar e também para o gosto, para as qualidades sensíveis, para as imagens, para os afectos, etc.; "arte" abre -se para a criação, imitação, génio, inspiração, valor artístico, etc. (TALON-HUGON, 2009, p.8)

Entretanto, enveredando-se pelo campo dos afetos, a Psicanálise se aproxima da Estética lembrando que ao lado do Belo está o Feio (ou o Horror). Freud, que no início do seu texto anunciou que estamos na fronteira da estética, denuncia em seguida que o estranho (Das Unheimliche) do qual ele se debruça tem uma natureza fugidia, radicalmente intraduzível, derrapante e que foge, inclusive, da precisão 
linguística, pois mescla-se ao seu oposto: Heimlich (familiar). Portanto, o familiar, o aconchegante, o conhecido, o apaziguador, o belo carrega em seu bojo o estrangeiro, o escondido, o perigoso, o feio. Eis a denúncia que Freud faz nesse texto.

Para dar conta desse paradoxo e dessa ambivalência, Freud recolhe da Literatura elementos que demarcam essa marca ex-tranha (exterior e entranha). Percebemos que o conto de E. T. A. Hoffmann (1776-1822), intitulado "O Homem de Areia”, ganha um espaço importante no argumento do texto sobre o estranho. Entretanto, nesse destaque que Freud faz ao conto "O Homem de Areia", queremos salientar uma distinção importante que ele aponta entre o estranho na literatura e o estranho vivido (na "vida real"). Assim, para Freud:

\begin{abstract}
O estranho, tal como é descrito na literatura, em histórias e criações fictícias, merece na verdade uma exposição em separado. Acima de tudo, é um ramo muito mais fértil do que o estranho na vida real, pois contém a totalidade deste último e algo mais além disso, algo que não pode ser encontrado na vida real. $O$ contraste entre o que foi reprimido e o que foi superado não pode ser transposto para o estranho em ficção sem modificações profundas; pois o reino da fantasia depende, para seu efeito, do fato de que o seu conteúdo não se submete ao teste de realidade. O resultado algo paradoxal é que em primeiro lugar, muito daquilo que não é estranho em ficção sê-lo-ia se acontecesse na vida real; e, em segundo lugar, que existem muito mais meios de criar efeitos estranhos na ficção, do que na vida real. (FREUD, 1996 [1919], p.310)
\end{abstract}

Freud nos diz que o escritor criativo tem a liberdade de escolher seu mundo de representação se aproximando ou se afastando da realidade, nesse cenário as figuras perdem a estranheza. Portanto, o estranho, nesse caso, é diferente da vivência de angústia e desamparo que se estabelece diante de um acontecimento. Dessa maneira, Freud nos adverte que:

A situação altera-se tão logo o escritor pretenda mover-se no mundo da realidade comum. Nesse caso, ele aceita também todas as condições que operam para produzir sentimentos estranhos na vida real; e tudo o que teria um efeito estranho, na realidade, o tem na sua história. Nesse caso, porém, ele pode até aumentar o seu efeito e multiplicá-lo, muito além do que poderia acontecer na realidade, fazendo emergir eventos que nunca, ou muito raramente, acontecem de fato. Ao fazê-lo, trai, num certo sentido, a superstição que ostensivamente superamos; ele nos ilude quando promete dar-nos a pura verdade e, no final, excede essa verdade. Reagimos às suas invenções como teríamos reagido diante de experiências reais; quando percebemos o truque, é tarde demais, e o autor já alcançou o seu objetivo. (FREUD, 1996 [1919], p.311) 
Isso nos impõe o segundo tempo desse trabalho: Tempo de escrever. Se recuperarmos a citação anterior, somos tomados por um ponto de enigma: como escrever a realidade? O que é o estranho na realidade e que "tanto" de realidade suportamos traduzidos no papel? Que truque é esse que nasce dos dedos do escritor?

Queremos advertir que a escrita de Carolina Maria de Jesus não obedece à norma culta da língua: as palavras imperiosas soam docemente desconectadas da gramática. Entretanto, algo insiste em se escrever. Enquanto se serve da escrita, na favela, Carolina era um constante desencaixe: lia, escrevia, catava papel e contabilizava diariamente a sua própria fome e a fome dos seus três filhos. Via-se como uma peça jogada no lixo, no despejo, mas escrevia... e, o tempo de escrever faz corpo. Essa escrita ressoava a outra escrita posta continuamente em negação por muitos: aquela que carrega a vasta história na pele negra e ordena que sua voz seja insistentemente silenciada.

Isso nos conduz a uma observação de Gérard Pommier (2002) que aponta que "se existe um sujeito, esse sujeito se define pela negação desse escrito, a negação do destino. Nós analistas estamos do lado desse sujeito que luta contra o destino, desse sujeito que diz não" (POMMIER, 2002, p.11). A escrita é uma das formas de dizer "não".

Nesse sentido, há que se estabelecer uma diferença entre escrever a realidade e escrever a verdade, uma vez que, como sabemos "a verdade tem estrutura de ficção" (Lacan, 1995 [1956-57), p.253). Das leituras possíveis que podemos fazer desse aforisma, Safatle (2006) demarca que "a verdade tem estrutura de ficção" deve ser lido com a ideia de que "o sujeito se fala com o seu eu". Assim, "a escrita é o retorno da perda de nossa imagem que ocorre quando falamos" (POMMIER, 2002, p.11), portanto escrever é se embaraçar com o estranho que "sou eu" definitivamente. Isso nos lança ao terceiro tempo: Tempo de estranhar.

Porque Freud escreveu Das Unheimliche? Esse texto que não se fecha, exterior, aberto, respirando, em movimento. Por que Carolina escreveu o des( $p$ )ejo? Por que cada um escreve? Talvez seja porque estranhamos. Estranhamos suportar um corpo marcado pelas insígnias do Outro, demarcado num tempo e espaço que escapa ao nosso controle. E é exatamente o Tempo de estranhar que nos coloca às voltas com a Psicanálise e com as "rondas dos semi-ditos", pois as voltas da psicanálise reafirmam a experiência da palavra. 
A verdade, essa que se apresenta semi-dita, não se suporta no dizer, não alcança o ponto último. A escrita tenta contornar esse resto indizível, esse estranhar que é colocar em movimento o desejo. O des( $p$ )ejo é sempre, segundo Freud, uma distância entre a satisfação esperada e a satisfação obtida, ou seja, é sempre uma falha de satisfação constitutiva do sujeito. Desse modo, o desejo é uma ausência radical de um objeto que complete, objeto sempre perdido. Resta o corpo...

Tempo de ler, tempo de escrever, tempo de estranhar. Às voltas... o que Freud nos adverte em seu texto e o que Carolina denuncia em sua letra é que estranho é sustentar o corpo próprio. Esse corpo que é habitado e habitável que circula pelas cidades entre outros corpos. Furado pelas marcas da pulsão, escrito e escritor. Corpo corrompido pelo desejo do Outro. Corpo sempre estranho, corpo de despejo. 


\section{REFERÊNCIAS}

DANTAS, A. Atualidade do mundo de Carolina. In Quarto de despejo: diário de uma favelada (1960). São Paulo: Editora Ática, 2001.

FARIAS, T. Carolina: uma biografia. Rio de Janeiro: Malê, 2017.

FREUD, S. (1919) O estranho. In Obras Completas da Edição Standard. Rio de Janeiro: Imago Editora, 1996. Volume XVII.

JESUS, C. M. Quarto de despejo: diário de uma favelada (1960). São Paulo: Editora Ática, 2001.

LACAN, Jacques (1956-57) O Seminário, Livro 4: A relação de objeto. Rio de Janeiro, Jorge Zahar Editor, 1995.

POMMIER, Gérard. Nacimiento y Renacimiento de la Escritura. Revista Literal. Campinas, número 5 - janeiro-junho/2002.

SAFATLE, V. A paixão do negativo: Lacan e a dialética. São Paulo: Editora UNESP, 2006.

TALON-HUGON, C. A estética: história e teorias. Lisboa: Edições Texto e Grafia, 2009. 


\title{
THE TRASH-WISH THAT INHABITS ME - PSYCHOANALYSIS AND THE ROUNDS
}

\begin{abstract}
The book "The Trash Room", written by Carolina Maria de Jesus, impacted society by revealing the reality of the slum. Therefore, what should remain hidden appears revealing a "strange fruit". We recover the first advice that Freud brings to us in his text Das Unheimliche (1919), announcing that society is on the frontier of aesthetics when dealing with the theme of the strange. However, the way in which Psychoanalysis approaches this theme reveals its elusive, radically untranslatable aspect. This work circulates between what Freud teaches us about the subject of the strange and what Carolina denounces by means of her letter: the close relationship between body and writing. In this sense, we situate the stranger in three stages: time to read, time to write, and time to wonder.
\end{abstract}

KEYWORDS: Carolina Maria de Jesus. Body. Writing. The uncanny. Psychoanalysis. 


\section{Le DePotolR QUI M'HABITE: LA PSYCHANALYSE Et LeS RONDS}

\section{RÉSUMÉ}

Le livre Le dépotoir: le journal intime de Carolina Maria de Jesus a impacté la société en révélant la réalité de la bidonville. Par conséquent, ce qui devrait rester caché s'apresent comme un "fruit étrange". Nous retrouvons la première annonce que Freud nous apporte dans son œuvre Das Unheimliche (1919), quand il souligne que nous sommes à la frontière de l'esthétique face au sujet de l'étrange. Cependant, la manière dont la psychanalyse aborde ce thème révèle son aspect insaisissable et radicalement intraduisible. Cet article circule entre ce que Freud nous apprend sur l'étrange et ce que Carolina dénonce avec ses paroles: la relation étroite entre l'écriture et le corps. En ce sens, nous articulons l'étrange en trois temps: le temps de lire, le temps d'écrire et le temps de s'interroger.

MotS-CLÉs: Carolina Maria de Jesus. Corps. Écrit. L'étrange. Psychanalyse. 
RECEBIDO EM 22/10/2020

APROVADO EM 24/11/2020

(C) 2020 Psicanálise \& Barroco em revista

http://www.seer.unirio.br/index.php/psicanalise-barroco/index revista@psicanaliseebarroco.pro.br

Programa de Pós-Graduação em Memória Social — UNIRIO

Memória, Subjetividade e Criação

www.memoriasocial.pro.br/proposta-area.php 